\title{
JOÃO ALFREDO CORRÊA DE OLIVEIRA: ENSINO TÉCNICO PROFISSIONAL E MODERNIZAÇÃO DA SOCIEDADE BRASILEIRA NO SEGUNDO REINADO
}

\author{
Ícaro Capanema de Faria \\ Pontifícia Universidade Católica de Minas Gerais \\ E-mail: icaro.capanema@gmail.com \\ DOI: 10.15628/rbept.2020.10057
}

Artigo submetido: em maio/2020 e aceito em: jul./2020

\begin{abstract}
RESUMO
Considerando-se o contexto brasileiro do fim do século XIX, destaca-se a preocupação de intelectuais e políticos em formar uma nova mão de obra livre, reflexo do processo gradual de abolição da escravatura. Em meio a esses intelectuais, destaca-se a figura de João Alfredo Corrêa de Oliveira e suas iniciativas direcionadas à educação profissional como importante fator de transformação da sociedade brasileira. Através de discursos escritos em relatórios políticos e de seu projeto de reforma da instrução primária e secundária em 1874, busca-se identificar suas várias significações relacionadas à educação profissional, além de estabelecer uma relação entre as escolas de ensino técnico profissional e a modernização do Império brasileiro.
\end{abstract}

Palavras-Chave: Educação Profissional. Modernização. História. João Alfredo.

\begin{abstract}
Considering the Brazilian context of the end of the 19th century, the concern of intellectuals and politicians to form a new free labor force, reflecting the gradual process of abolishing slavery, stands out. Among these intellectuals, João Alfredo Corrêa de Oliveira and his initiatives aimed at professional education as a important factor in the transformation of Brazilian society stand out. Through speeches written in political reports and his project to reform primary and secondary education in 1874 , he seeks to identify its various meanings related to vocational education, in addition to establishing a relationship between vocational schools and the modernization of the Brazilian Empire.
\end{abstract}

Keywords: Professional Education. Modernization. History. João Alfredo. 


\section{INTRODUÇÃO}

É durante o Segundo Reinado, no último quartel do século XIX, essencialmente após a Lei do Ventre Livre de 1871, no contexto em que o processo de abolição gradual da escravidão vai chegando ao fim, que a preocupação com a inserção da mão de obra livre em detrimento do trabalho escravo, aliado à industrialização e, consequentemente, a uma modernização do Brasil, cresce nos discursos de intelectuais e estadistas brasileiros. A inquietação deles terá como consequência todo um projeto de nação calcado na defesa da disseminação da instrução básica, secundária e profissional, tendo esta última modalidade objetivos específicos que vão, desde o assistencialismo e a ordem pública, até o desenvolvimento de uma nova mão de obra brasileira.

Nesse quadro, surge a figura de João Alfredo Corrêa de Oliveira, importante estadista do Segundo Reinado e que, a partir de seus discursos e de seu projeto de reforma da instrução primária e secundária, do ano de 1874, pode ser identificado à relação que se estabelece entre escolas de ensino técnico profissional e modernização do Brasil.

\section{TRAJETÓRIA DE JOÃO ALFREDO}

É como "estadista da abolição" que João Alfredo Corrêa de Oliveira costuma ser referenciado na historiografia brasileira. Isso acontece de fato por seu nome estar ligado ao processo de abolição da escravatura. Esteve presente como Ministro do Império no Gabinete Rio Branco, responsável por promulgar a Lei do Ventre Livre, e também no Gabinete de 10 de Março como seu Presidente, que promulgou a Lei Áurea em 13 de maio de 1888, cabendo ao próprio João Alfredo, como apontado pelo Dicionário bibliográphico brazileiro, de Blake (1902), a "honra de apresentar à princesa regente o decreto que aboliu a escravidão no Brazil". (BLAKE, 1902, p. 316).

O jornal $O$ Globo, no ano de 1874, traz uma biografia detalhada de João Alfredo, pela autoria de alguém que se identifica com o pseudônimo de Junius e que irá, de fato, colocar o "estadista da abolição" em local de destaque ao lado do próprio Rio Branco. Entretanto, sua posição de prestígio neste caso será enfatizada por outro motivo que vai além da lei do Ventre Livre: sua preocupação com a instrução pública. Comparando os dois sujeitos, o autor diz respectivamente:

A um se deve a grande lei que no frontespicio tem o eloquente dístico: 'De hoje em diante ninguém mais nasce escravo na terra de Santa Cruz'; ao outro esse movimento a favor da instrução pública que, segundo a frase do grande publicista americano, 'será só capaz de desarmar a selvageria deste futuro exército de 
eleitores, cuja ignorância pode ameaçar a melhor organização social e política'. (O Globo, 10 de Setembro de 1874).

João Alfredo, em sua obra Minha Meninice ${ }^{1}$ afirma sua descendência de gerações de senhores de engenho, pertencendo às famílias influentes e que, consequentemente, detinham a riqueza e o poder político local. O historiador Manuel Correia de Andrade (1988), em biografia dedicada ao político, intitulada "João Alfredo: o estadista da abolição" aponta que foi a criação de João Alfredo em meio ao ambiente conturbado da Revolta Praieira que o fez se interessar pela política e também a tornar-se um "ardente conservador". (ANDRADE, 1988, p. 30).

Segundo José Murilo de Carvalho² (1981), é em meio ao ambiente das consequências geradas pela descentralização efetivada pelo Código de Processo Criminal de 1832 e pelo Ato Adicional de 1834, e das rebeliões provinciais, como a Revolta Praieira vivenciada por João Alfredo em 1848, que será possibilitada a formação dos dois grandes partidos que dominaram a vida política do Império até o seu fim: o Partido Liberal e o Partido Conservador, ao qual João Alfredo filiou-se durante a vida.

Andrade (1988) destaca como prelúdio da vida política de João Alfredo quando, em 1857, seu sogro e tio, o Coronel João Joaquim da Cunha Rego Barros, adquire uma propriedade a quatro quilômetros do centro de Recife com o objetivo de, além de inserir um de seus filhos no comércio local, também iniciar o genro João Alfredo na política. A partir daí, Rego Barros encaminha-o, sob a proteção do Visconde de Camaragibe, líder conservador que controlou durante décadas a política do partido em Pernambuco.

Levando em consideração todo seu empenho à política, João Alfredo construiu uma figura de grande destaque no interior do Partido Conservador, se tornando um de seus mais influentes estadistas. $\mathrm{Na}$ explícita apologia aos conservadores do Império realizada pelo historiador João Camillo de Oliveira Torres, na sua obra "Os Construtores do Império" (1968), João Alfredo aparece como um dos conservadores de "primeira plana" ao lado de vários outros, até mesmo do próprio fundador do partido, Bernardo Pereira de Vasconcelos.

Para o presente artigo, é de maior interesse a sua posição enquanto Presidente do Liceu de Artes e Ofícios do Rio de Janeiro, que se deu concomitantemente às suas diversas funções no Império durante praticamente toda sua carreira. Outro papel de destaque se encontra na iniciativa de criação, enquanto Ministro do Império, do Asilo de Meninos Desvalidos, inaugurado em 14 de Março de $1875^{3}$, que posteriormente veio a ter o nome de Instituto João

\footnotetext{
1 João Alfredo Corrêa de Oliveira, Minha Meninice (1949)

2 A Construção da Ordem: a elite política imperial (1981)

${ }^{3}$ Decreto n.. 5.532 de 24 de Janeiro de 1874, Gabinete Rio Branco.
} 
Alfredo em sua homenagem. Tarquínio de Souza Filho, intelectual contemporâneo ao estadista e autor de O Ensino Technico no Brasil, de 1887, define João Alfredo e o estabelecimento criado, através da iniciativa do mesmo, da seguinte maneira:

Um estabelecimento que entre nós também distribui, a par do ensino profissional, a instrução literária e científica, é o Asilo de Meninos Desvalidos, a cargo do Ministério do Império e criado por decreto n. 5.532 de 24 de Janeiro de 1874, por inspirada e patriótica iniciativa do ilustrado Sr. Conselheiro João Alfredo Corrêa de Oliveira, um dos nossos estadistas, que melhor tem compreendido, com verdadeira e clara intuição, as necessidades atuais do país e suas aspirações futuras. (SOUZA FILHO, 1887, p. 84).

Em Agosto de 1888, quando é veiculada no Jornal do Comércio do Rio de Janeiro uma notícia com o suposto encerramento das atividades do Liceu de Artes e Ofícios, a discussão vai até o Senado e parlamentares questionam João Alfredo sobre a situação do Liceu. Antes de tudo se esclarecer como apenas um mal entendido, são tecidos certos enaltecimentos à instituição de ensino profissional. O senador Cândido de Oliveira a referência da seguinte maneira:

O Liceu de Artes e Ofícios é uma instituição modelo como organização e merecedora da gratidão pública pelos imensos e inapreciáveis benefícios que tem prestado, especialmente às classes desfavorecidas da fortuna. Suprimi-lo hoje, estancar subitamente esta abundante fonte de instrução popular, é quase tentar o impossível. (ANAIS DO SENADO DO IMPÉRIO, vol. IV, 1888).

É através dessa inquietação com o ensino e, principalmente, com o ensino profissional, apresentada por suas iniciativas enquanto presidente do Liceu de Artes e Ofícios do Rio de Janeiro, pela criação do Asilo de Meninos Desvalidos e pela tentativa de implementar um projeto de reforma para a educação que João Alfredo se torna uma figura de destaque entre os conservadores, além de extremamente relevante para o estudo do ensino profissional e sua relação com a "modernização" do Brasil.

$\mathrm{Na}$ tentativa de definir quem se constituía como liberal ou conservador no Império brasileiro, e quais eram as suas origens e posições em meio à política e 
à sociedade, José Murilo de Carvalho (1981) levanta as três concepções tradicionais quanto ao tema na historiografia brasileira. Respectivamente, existem os que negam qualquer diferença entre os partidos, representados por Caio Prado Junior (1933), Nelson Werneck Sodré (1968), Nestor Duarte (1939), Maria Isaura Pereira de Queiroz (1957) e Vicente Licínio Cardoso (1924); os que empregam distinções em termos de classe social, representados por Raymundo Faoro (1958), Azevedo Amaral (1938) e Afonso Arinos de Melo Franco (1972); e os que distinguem por outras características, como a origem regional ou a origem rural/urbana, representados por Fernando de Azevedo (1943) e João Camillo de Oliveira Torres (1968).

Todavia, ao levantar as ocupações, as origens sociais e regionais dos políticos filiados a seus respectivos partidos, Carvalho (1981) sintetiza desta forma a composição partidária no Império:

Os partidos imperiais, em sua liderança nacional, compunhamse de intrincada combinação de grupos diversos em termos de ocupação e de origem social e provincial. Não cabem a seu respeito divisões e classificações simplificadas. A complexidade dos partidos se refletia naturalmente na ideologia e no comportamento político de seus membros, dando às vezes ao observador desatento a impressão de ausência de distinção entre eles. Um exame, embora sumário, de alguns problemas cruciais enfrentados pelos políticos do Império pode, no entanto, mostrar tanto as divergências interpartidárias como intrapartidárias. (CARVALHO, 1981, p. 171).

Para exemplificar essa diferença "intrapartidária", Carvalho (1981) aponta para aqueles membros do Partido Conservador que tendiam a favorecer reformas sociais ao mesmo tempo em que, a partir de um elemento burocrático, buscavam a centralização e a unicidade do Império, como Visconde do Uruguai, Pimenta Bueno e Nabuco de Araújo, políticos distintos de outros também conservadores e que, em contraponto, negavam reformas deste perfil, como 0 escravagista João Maurício Wanderley, barão de Cotegipe. Outra possível referência para evidenciar a distinção entre os membros de um mesmo partido é a cisão sofrida pelo Partido Conservador a partir da reação à Lei do Ventre Livre de 1871, realizada pelo já citado Gabinete Rio Branco4.

É em meio a esta complexidade de definição daqueles sujeitos que compunham os partidos dominantes durante o período Imperial brasileiro que se encontra a figura de João Alfredo, "o conservador que fez a Abolição" (Torres,

\footnotetext{
4 José Murilo de Carvalho, $A$ construção da Ordem: a elite política imperial (p. 174, 1981)
} 
1968, p. 34). Não é a toa que autores como o próprio Torres ${ }^{5}$, e o de pseudônimo Junius do jornal $O$ Globo (1874) chegaram a fazer analogias que inseriam a figura de João Alfredo em meio aos políticos que, supostamente, deveriam realizar reformas ditas "liberais" no Brasil, tendo como base uma definição partidária genérica, negando sua complexidade e a peculiaridade de cada sujeito político do Império.

\section{O PROJETO DE JOÃO ALFREDO E SUAS SIGNIFICAÇÕES}

Em relatório apresentado por João Alfredo à Assembleia Geral como Ministro do Império no ano de 1873, o mesmo já se referia ao projeto de reforma da educação6: "Para melhorar a instrucção primária, secundaria e profissional formulei um projeto, que brevemente submeterei á vossa ilustrada consideração, e no qual lancei as bases da reforma que me parece dever ser adotada e que peço autorização para levar a efeito no município da Corte". (ASSEMBLEIA GERAL, 1873).

O projeto de lei ${ }^{7}$ é apresentado à Assembleia Geral Legislativa em 23 de julho de 1874, com o objetivo geral de reorganizar o ensino primário e secundário em todo o Império. Antes de discorrer item por item as propostas de João Alfredo que consistem no projeto, interessante observar o discurso da Comissão de Instrução Pública - setor ao qual o projeto foi primeiramente remetido - em relação à proposta.

Os pareceres que a Comissão de Instrução Pública faz ao projeto irão sempre destacar como a aplicação da reforma poderia implementar a "Ordem, moralidade e progresso" no Império, comparando a iniciativa de João Alfredo com a de outros países ditos centrais e "civilizados". A influência estrangeira, que irá aparecer no projeto de reforma, aparece também nos dizeres da Comissão:

[...] Todos os governos dos países civilizados, e de todos os tempos teem envidado os maiores esforços para que desapareça aos seus cuidados essa causa primordial dos males sociais, para que ao menos os membros da sociedade, cujos

\footnotetext{
5 João Camillo de Oliveira Torres, Os construtores do Império (1968)

${ }^{6}$ Discutindo a utilidade de discursos e projetos políticos como fontes históricas, Ângela Malheiro (2015) aponta: "O interesse na análise dos discursos políticos recai não só na perspetiva da construção de uma racionalidade política e da regulação de factos políticos que visem determinar as estratégias de ação e de poder, mas também, e é o que nos interessa, na reconhecida importância como fonte histórica, sendo um importante instrumento de análise de um determinado tempo e espaço históricos". (MALHEIRO, 2015, p. 13).

7 Projeto oํ 73-A, disponível nas Obras completas. Vol. IX, tomo I de Rui Barbosa (1942)
} 
destinos eles dirigem, adquiram os conhecimentos elementares da leitura e da escrita. (BARBOSA, 1942, p. 336).

Quanto à instrução elementar, equivalente aos ensinamentos de leitura, escrita e aritmética básica, a Comissão a considera como condição igual a todos, mesmo tendo consciência de que as necessidades são diferentes conforme as classes, os indivíduos e as aptidões. A instrução primária torna-se igual para todos mesmo levando em conta os fins para que cada um se prepare, sendo 0 analfabeto uma "espécie de cego de espírito", e "propenso à prática dos vícios e dos crimes". Assim sendo, a Comissão aprova o projeto de João Alfredo e pede que se adote o mencionado projeto sem alteração, e nos termos em que seu autor o formulou.

O projeto conta com 15 itens, nos quais João Alfredo apresenta suas propostas para a reforma na educação. O primeiro deles diz respeito à liberdade do ensino particular no município da corte, ficando sujeitos à inspeção para verificar se preenchem as condições necessárias de moralidade e higiene. $O$ segundo item define o ensino primário elementar como obrigatório no município da corte, para todos os indivíduos de 7 a 14 anos e para os de 14 a 18 anos que ainda não o haviam obtido.

Ainda se tratando do segundo item, João Alfredo irá definir todo um regulamento e condições para os pais dos alunos, que estarão sujeitos à multas caso não enviem seus filhos para as instituições de ensino, podendo também educá-los em suas próprias casas ou estabelecimentos particulares, desde que sejam submetidos por um inspetor literário a provas no fim de cada ano. $O$ projeto também define a instrução primária dos operários, que deverá ser obrigatória e estar sob responsabilidade dos donos de fábricas.

O terceiro item divide a instrução primária no município da corte em primária elementar e primária superior, ambas com o programa reformulado pelo próprio governo do município. O quarto item diz respeito à fundação de novas escolas no município da corte, que funcionariam exclusivamente para a educação de adultos e que poderiam abrir no horário diurno bem como no noturno.

Em relação à educação profissional, sua preocupação começa a se destacar a partir do quinto item do projeto, em que se define que deveria ser criadas, nos municípios das províncias do Império, escolas profissionais em que se ensinariam as ciências e suas aplicações que mais convierem às artes e indústrias dominantes ou que devam ser criadas e desenvolvidas. Interessante notar que sua preocupação com a instrução pública aparentemente se concentra apenas no município da corte, enquanto a instrução profissional para ele deve se alastrar por todos os municípios do Império. 
O sexto item define que para manter as escolas profissionais será criado respectivamente um tipo de "caixa" em cada municipalidade, cuja renda será constituída por uma parcela da contribuição de pessoas que viverem do trabalho e das rendas da escola profissional, por donativos particulares, por benefícios gerais e provinciais que forem concedidos para o mesmo fim, e por uma porcentagem sobre o produto dos impostos gerais. Caso um município não consiga verba suficiente para manter uma escola profissional, o sétimo item define que esse município poderá reunir-se com outros 2 ou 3 e estabelecer uma só escola. Se ainda assim, o que for arrecadado ainda não seja o suficiente, o governo poderá conceder pequenos subsídios à escola.

A fiscalização da escola profissional, como exigido pelo oitavo item, ficará sob responsabilidade de um conselho administrativo formado por 1 membro eleito em cada paróquia, 2 eleitos pela câmara municipal, 1 diretor da escola e um inspetor nomeado pelo presidente da província. Os itens nove e dez definirão que o diretor da escola será nomeado pelo presidente da província, assim como os professores, mediante concursos realizados na capital.

O item onze define que serão criadas nos municípios da Corte duas escolas normais, uma para cada sexo, nas quais serão preparados professores para o ensino primário. $O$ décimo segundo item define que o governo poderá: fundar no município da corte escolas mistas; instituir escolas de trabalho para o sexo feminino; auxiliar estabelecimentos particulares de ensino primário e profissional; conceder aos estabelecimentos de instrução secundária, mantidos pelas províncias, e que seguirem o plano de estudos do Colégio Pedro II, as mesmas vantagens de que goza este Colégio; conceder favores que julgar convenientes aos cursos preparatórios exigidos para a matrícula nos cursos superiores; determinar que sejam admitidos a exames no Imperial Colégio de Pedro II, e dos que semelhantemente se fundarem nas províncias, todos os que requererem; extinguir os cursos preparatórios anexos às faculdades de Direito; fundar e auxiliar, em todo o Império, bibliotecas populares; e encarregar intectuais e professores de visitarem os estabelecimentos de instrução primária, secundária e especial de nações estrangeiras.

O décimo terceiro item admite alguns funcionários a mais na Secretária de Instrução Primária do município da corte, enquanto o décimo quarto divide o mesmo município em distritos literários, tantos quantos fossem necessários para uma assídua fiscalização. O décimo quinto e último item define que o conselho diretor da instrução primária será composto dos reitores do Imperial Colégio de Pedro II, dos inspetores literários, de um professor público, de um professor particular, de dois cidadãos habilitados e do inspetor geral que será o presidente.

Através da leitura sistemática do projeto de lei de João Alfredo é possível destacar várias características importantes e que lhe conferem destaque. A primeira delas é a obrigatoriedade do ensino elementar no município da corte e sujeição a multas para aqueles que não enviassem seus filhos para as escolas. Cynthia Veiga, historiadora e autora de "História da Educação" (2007), aponta a 
função e o dever do Estado quanto à instrução básica no Segundo Reinado como praticamente nulo, já que, fornecer este tipo de instrução primária já não cabia ao Império, mas sim à cada província, mudança causada pela descentralização administrativa do Ato Adicional de 1834. Assim sendo, pode se considerar a obrigatoriedade do ensino elementar e a implementação de escolas de várias modalidades - normais ${ }^{8}$, mistas e adultas - como um tipo de "padrão" a ser correspondido pelo restante do país.

A obrigatoriedade do ensino para crianças e adultos que ainda não houvessem obtido a instrução básica, pode ser compreendida como uma tentativa de minimizar a dificuldade encontrada ao instruir essa população livre e pobre do Império. Além da baixa frequência por parte dos alunos, principal obstáculo encontrado na difusão da instrução básica na segunda metade do século XIX, havia também "falta de professores qualificados, material escolar adequado e edificações adaptadas à sistemática das aulas". (VEIGA, 2007).

A ausência de alunos nas escolas públicas do Império pode ser interpretada como resultado da condição de pobreza em que vivia a maioria das crianças e adolescentes. Cynthia Veiga (2007) aponta que "a possibilidade de frequência à escola por parte dos alunos dependia das condições materiais de vida dos alunos". (VEIGA, 2007, p. 152). Assim sendo, seria mais interessante para esses núcleos familiares se seus filhos, no lugar de frequentarem escolas, trabalhassem e ajudassem os pais com as despesas de casa.

Para que se pudesse cobrar dos pais e responsáveis pelas crianças a obrigatoriedade no ensino, João Alfredo alegava que seria necessário um aumento da oferta de escolas com vagas suficientes, por isso a criação de escolas normais e escolas mistas para ambos os sexos, além de escolas para a instrução de adultos, ambas no município da Corte. Em relatório feito como Ministro do Império em 1871, João Alfredo diz:

Certamente enquanto não se fundarem tantas escolas públicas gratuitas quantas forem necessárias para que se torne possível e fácil a sua frequência aos meninos de todas as localidades, o emprego de meios coercitivos para que pais e pessoas que tiverem menores sob a sua direção the deem o ensino elementar, seria uma clamorosa violência, principalmente em relação às classes, cujos deficientes recursos não comportam os dispêndios que exige aquele ensino dado particularmente. (MOACYR, 1937, p. 103).

\footnotetext{
${ }^{8}$ Escolas destinadas à formação de professores 
Na perspectiva de João Alfredo, na medida em que os impedimentos relacionados à difusão da instrução fossem diminuídos paulatinamente, seria possível construir proporcionalmente uma nova "moral do trabalho", necessária não só para o desenvolvimento da Indústria, mas para o desenvolvimento do Império como um todo. A obrigatoriedade para parte dos adultos, principalmente para aqueles que se dedicariam ao trabalho industrial nas fábricas, e a criação de escolas noturnas, destinada àqueles que trabalhavam durante todo o período diurno, são reflexos de todo um projeto Nação que educasse desde criança um novo trabalhador brasileiro e que, assim, consequentemente se instrumentalizasse de forma moral e profissional.

Em se tratando especificamente da educação profissional no projeto, é interessante destacar, como já citado, a diferença de tratamento do estadista entre instrução básica e primária e a instrução profissional. A instrução profissional em seu projeto não aparece de forma obrigatória como a instrução primária, mas em contraponto, o projeto de lei define que todos os municípios das províncias do Império devam implementar escolas profissionais.

Destaca-se ainda no projeto de lei de 1874 outras características que empregavam peculiaridade ao projeto e distinguiam João Alfredo no debate em torno da educação no Império, como a criação de escolas para o sexo feminino, a formação de bibliotecas populares em todo o Império, a equiparação ao colégio Imperial Pedro II para todas aquelas instituições secundárias que utilizassem seu plano de estudos - medida que aparece de maneira bem semelhante na reforma Francisco Campos, 57 anos mais tarde - e o envio de intelectuais e professores a outros países "civilizados", a fim de visitar estabelecimentos de instrução em geral.

Em outros discursos de João Alfredo, é possível notar um destaque com relação à difusão de escolas profissionalizantes em todo o Império, como é proposto em seu projeto de lei. Porém, ao mesmo tempo em que se evidencia 0 caráter de assistencialismo associado às escolas profissionais, também se torna claro o viés de desenvolvimento do Império e da formação de um novo trabalhador brasileiro. Quando Rangel Pestana, no ano de 1886, se queixa da falta de valorização do Liceu de Artes e Ofícios de São Paulo, João Alfredo destaca a instituição da seguinte maneira em seu relatório como presidente da província:

O ilustrado Sr. Dr. Rangel Pestana, presidente da diretoria, lamenta que os esforços e a dedicação que a sociedade propagadora da instrução popular tem merecido o Liceu não hajam sido compreendidos pela população, nem secundados por aqueles que se acham no caso de auxiliar generosamente este estabelecimento, onde o ensino é dado a todas as classes pobres, sem distinção de crenças, sem fins de propaganda e somente por amor ao próximo, pelo desejo de elevar o nível 
moral das classes trabalhadoras e de aperfeiçoar a mentalidade popular. (PROVÍNCIA DE SÃO PAULO, 1886).

Patto (2007), em artigo denominado "Escolas cheias, cadeias vazias: nota sobre as raízes ideológicas do pensamento educacional brasileiro", faz um estudo comparativo entre as propostas de reformas educacionais do Segundo Reinado brasileiro e as de atualmente. A autora destaca o aspecto de longa duração presente nos projetos de reformas educacionais no Brasil no que diz respeito à ordem pública. Segundo Patto (2007), a instrução com o intuito de "prevenção da criminalidade", aspecto que, ainda segundo a autora, sempre esteve presente nos projetos de educação nacionais, praticamente anula a escola como instituição que tem o dever de garantir o direito de todos ao letramento e ao saber.

De fato, nos discursos e no projeto de reforma educacional de João Alfredo, características ligadas ao assistencialismo e à ordem pública irão se destacar direta ou indiretamente em vários momentos. Em relatório escrito como Presidente da Província de Pará de 1870, João Alfredo referência um estabelecimento de instrução profissional para órfãos e desvalidos no Maranhão da seguinte maneira:

Um estabelecimento desta ordem, que produz magníficos resultados na província do Maranhão, d'onde segundo me consta, foi tirado o modelo para outro na província do Amazonas, não só custaria pouco aos cofres provinciais, mas também faria de tantos órfãos e meninos pobres, que aí vagão sem direção e sem aplicação útil, bons artistas de que a província tanto carece e cidadãos morigerados. (PARÁ, Typographia do Diário do Gram Pará, 1870).

Entretanto, não só características ligadas ao assistencialismo e à ordem pública se evidenciam nos discursos de João Alfredo. A iniciativa da criação de escolas profissionais em todos os municípios do Império proposta no projeto de reforma do ensino pelo estadista é prova irrefutável disso. Aliando assistencialismo e ordem pública, a instrução profissional poderia, como já citado anteriormente, além de qualificar e inserir ex-escravos, elevar o trabalhador brasileiro a uma nova moral, desenvolvendo assim a indústria brasileira, de modo a modernizar o Brasil nos moldes do capitalismo, tendo como referência os países considerados "centrais": Inglaterra, França, Alemanha, Estados Unidos etc.

Somando assistencialismo, mais ordem pública e desenvolvimento econômico, encontra-se como resultado o projeto Nação pretendido por João 
Alfredo em seu projeto de lei e seus discursos, e pela maioria daqueles outros intelectuais e políticos que pensam o ensino profissional no último quartel do século XIX, como Tarquínio de Souza Filho ${ }^{9}$ e Rui Barbosa ${ }^{10}$.

\section{O ANDAMENTO DO PROJETO E SUA REPERCUSSÃO}

Após aprovado pela Comissão de Instrução Pública, o projeto vai à debate na Câmara em maio de 1875. Primitivo Moacyr (1937), historiador brasileiro dedicado à História da Educação no Brasil, aponta o debate político em torno do projeto entre o pernambucano Cunha Figueiredo Junior e o alagoano Teixeira Rocha. O primeiro desfere severas críticas ao projeto, principalmente no que tange às despesas que a reforma impõe, à intervenção na jurisdição das províncias, à liberdade do ensino, que supostamente "abre as portas do charlatanismo e à impiedade", à falta de ensino religioso, à obrigatoriedade de ensino, às escolas de trabalho para o sexo feminino e às escolas mistas. Destaca-se no discurso de Cunha Figueiredo Junior a resistência das famílias consideradas pobres em mandar seus filhos para a escola, uma vez que eles poderiam trabalhar e ajudar com o sustento de seus familiares ao invés de se dedicar aos estudos:

As famílias pobres, e estas são em maior número, podem não ter meios para mandar seus filhos à escola; com grande sacrifício conseguem mantê-los, tendo em compensação a sua companhia e os pequenos serviços que eles podem prestar (MOACYR, 1937).

Em resposta à Cunha Figueiredo Junior, o deputado e também professor da Faculdade de Medicina da Corte, Teixeira Rocha, defende o projeto pela argumentação de que não há intervenção nas províncias, já que o projeto se refere principalmente à reforma do ensino primário e secundário do município neutro. Segundo o deputado, o que no projeto existe e que se extende às províncias não pode ferir os direitos das assembleias provinciais. Além disso, afirma não observar no projeto o que possa favorecer a "impiedade" citada por Cunha Figueiredo Junior. Para finalizar, Teixeira Rocha ainda justifica a obrigatoriedade do ensino requisitada pelo projeto:

\footnotetext{
${ }^{9}$ O Ensino Technico no Brasil (1887)

${ }^{10}$ Reforma do Ensino Primário. In: Obras Completas de Rui Barbosa. (1942) 
Os pais que podem dar educação aos filhos e não tratam de o fazer, por desleixo ou motivo frívolo, de pequeno interesse, resultantes dos serviços que eles porventura lhes prestem, merecem as penas consignadas no projeto, que aliás não são rigorosas, e mais ainda. (MOACYR, 1937)

Ainda segundo Moacyr (1937), após debate na Câmara dos deputados, o projeto e emendas voltaram à Comissão de Instrução Pública para que seja mediado parecer. Posteriormente, o projeto não aparece mais nos anais da Câmara dos Deputados, fazendo com que o andamento da reforma de João Alfredo se torne "não sucedido", como apontado por Fonseca" ${ }^{11}$ (1961) e Cunha (2000).

Assim sendo, é possível levantar algumas hipóteses para o não andamento do projeto de João Alfredo através de análise da imprensa e do debate em torno da educação em geral realizado por intelectuais e políticos do último quartel do século XIX.

Voltando à biografia de João Alfredo encontrada em algumas edições do jornal $O$ Globo em 1874, o autor anônimo que assina como Junius destaca um dos possíveis motivos pelo qual o projeto possa ter sido mal sucedido:

Essa grande ideia contida no projeto de lei apresentado ao parlamento na sessão do corrente ano, ainda não será realizada em breve como o ministro a desejava, por causa dos mil tropeços constantemente levantados pelos oposicionistas, que julgam servir a causa pública impedindo a passagem de toda a medida útil só pelo fato de ser ela iniciada pelo ministro que tão alto tem elevado o seu nome. ( $O$ Globo, 10 de Setembro de 1874).

Angela Alonso (2002) ressalta as dificuldades encontradas por parte da geração de 1870, principalmente por aqueles que compuseram o Ministério de Rio Branco, ao qual na tentativa de modernizar a sociedade brasileira e a economia, encontravam uma dupla resistência, gerando o que a autora chama de "modernização descompassada"12. Os sujeitos políticos que tentaram no início da crise do Império desenvolver uma reforma controlada que não

\footnotetext{
${ }^{11}$ Celso Suckow da Fonseca, História do Ensino Industrial no Brasil (1961)

${ }^{12}$ Angela Alonso, Ideias em Movimento: a geração 1870 na crise do Brasil Império (p. 94, 2002) 
contestasse a lógica do sistema, encontraram oposição de ambos os lados, tanto dos conservadores quanto dos liberais.

Da parte conservadora, os mais reacionários que viam o próprio partido defendendo bandeiras liberais, contestavam as propostas reformadoras e aqueles que as tentavam executar. Já da parte liberal, vendo uma boa quantidade de seus programas avançarem em mãos conservadoras, investiram contra as instituições saquaremas e em seu status quo, o que acabou por agravar ainda mais a crise do Império nos fins do $\mathrm{XIX}^{13}$.

É nesse extrato intermediário que se encontra João Alfredo e seu projeto, onde possivelmente teve resistências tanto do lado conservador, partido do qual o estadista era membro, quanto do lado liberal, que tentava de toda maneira frear reformas que, mesmo sendo iguais às que reivindicavam, não poderiam ser executadas pelo lado politicamente oposto.

Entretanto, não se deve creditar o não andamento do projeto de João Alfredo unicamente como consequência de uma resistência política. O projeto também sofreu críticas além daquelas desferidas por Cunha Figueiredo Junior durante debate na Câmara dos Deputados. O periódico A Instrução Pública que, como apontado por Bastos ${ }^{14}$ (2009), é um dos representantes da chamada "imprensa pedagógica", irá analisar o projeto de João Alfredo e destacar pontos negativos.

As críticas desferidas pelo periódico que, ainda segundo Bastos (2009), se constitui e tem como núcleo de leitores os educadores, professores e intelectuais do Império, são direcionadas a alguns aspectos do projeto de reforma de João Alfredo e, sem apontar motivos, não se aprofundam e nem demonstram argumentos na maioria das afirmações ${ }^{15}$.

Os pontos negativos, segundo $A$ Instrução Pública, são: o fato de "João Alfredo não conseguir enxergar o ensino em sua substância, em seu âmago, e sim de forma exterior, à superfície"; o fato de "não inovar em nada o ensino em si"; "as grandes despesas que o projeto iriam causar; a liberdade ao ensino particular, sendo que fiscalizar apenas questões relacionadas à moral e à higiene não convêm ao que os pais dos alunos desejam"; o fato de que "não é o município neutro que mais carece da medida de ensino obrigatório, e sim nos municípios do interior"; o fato de que "não se deve criar escolas profissionalizantes em todos os municípios antes de se ter um número de escolas primárias suficientes nos mesmos"; e o fato de que "o plano de estudos

\footnotetext{
${ }^{13}$ Angela Alonso, Ideias em Movimento: a geração 1870 na crise do Brasil Império (p. 167, 2002)

${ }^{14}$ Maria Helena Camara Bastos, A Instrução Pública (1872-1875/1887-1888): permuta de luzes e ideias, os editoriais de Alambary Luz (2009)

15 Destaca-se que, na edição do periódico em que se encontram as críticas ao projeto de reforma de João Alfredo, afirma-se que, nas próximas edições do jornal, seriam desenvolvidas de maneira mais aprofundada suas considerações acerca do projeto, o que não acontece de fato, sem explicação aparente.
} 
do Colégio Pedro II não vale a despesa de ser exemplo para outras instituições secundárias".

Bastos (2009), destacando como o estudo da chamada "imprensa pedagógica" pode contribuir para as pesquisas acerca da História da Educação, aponta que:

O estudo do lugar da imprensa pedagógica no discurso social, as estratégias editoriais face aos fenômenos educacionais e sociais revelam-se, assim, ricos de informações ao pesquisador para o resgate do discurso pedagógico, das práticas educacionais, do cotidiano escolar, do grau de submissão dos professores aos programas e às instruções oficiais, da ideologia oficial e do corpo docente, da força de inovação e continuidade que representa, das contradições do discurso. (BASTOS, 2009, p. 2).

Se tratando de um periódico que é dirigido por intelectuais, professores e educadores em geral, e que se direciona a leitores também relacionados à instrução, não se deve ignorar a relevância dessa análise realizada no contexto do Segundo Império e também as fragilidades encontradas no projeto de João Alfredo. Portanto, essas instabilidades encontradas na reforma, mesmo não sendo esclarecidas de uma maneira mais aplicada pelo periódico, podem também ter influenciado para o seu não andamento.

Cabe ainda dar um destaque maior ao obstáculo financeiro que o projeto possa ter encontrado. Tanto na análise do periódico $A$ Instrução Pública, quanto nas duras críticas de Cunha Figueiredo Junior na Câmara dos Deputados, encontra-se o problema das despesas que o projeto acarretaria aos cofres públicos. Mesmo tentando resolver essa adversidade no próprio projeto, com a criação de "caixas" que sustentariam as escolas profissionais em todos os municípios, por exemplo, a reforma de João Alfredo acaba sofrendo bastante nesse aspecto.

Assim como havia, além da dificuldade das condições materiais, uma enorme resistência de parte da população em enviar seus filhos para as escolas, desacreditando em grandes proporções nos benefícios que a instrução poderia trazer, ressalta-se também uma semelhante resistência por parte de políticos e estadistas brasileiros do século XIX. Chamon (2014) ${ }^{16}$ aponta que, mesmo com a ausência de oposicionistas da questão profissionalizante, o quesito financeiro e a quem caberia a manutenção desses estabelecimentos afirmavam uma "resistência ao comprometimento das finanças do Estado num setor - formação de mão de obra - que, em tese, beneficiaria principalmente a iniciativa particular." (CHAMON, 2014, p. 588).

${ }^{16}$ Carla Simone Chamon, Escolas de Artes e Ofícios Mecânicos em Minas Gerais (2014) 
Mesmo a reforma de João Alfredo não tendo sido aprovada e colocada em prática, e mesmo a saída de João Alfredo do Ministério um ano após a tentativa de aprovação do projeto de lei, os aspectos inovadores da reforma e a iniciativa do estadista ecoaram pelo Império e se tornaram exemplo para intelectuais e objeto de discussões acerca da instrução pública e da educação profissional entre esses sujeitos.

Citações acerca do projeto de João Alfredo de 1874 irão aparecer em várias ocasiões a partir de sua discussão na Câmara dos Deputados e de seu não andamento. Rui Barbosa, por exemplo, irá citar e destacar a reforma João Alfredo em seus Pareceres/Projetos sobre a educação, na "Reforma do Ensino Secundário Superior" (1942), até mesmo reservando espaço para inserir o projeto integralmente em suas páginas.

\section{POSICIONAMENTO DE JOÃO ALFREDO NA CRISE DO IMPÉRIO}

Alonso (2002) irá apontar uma completa indissociabilidade entre as esferas intelectuais e políticas durante o período da crise do Império na geração de 1870. Os discursos de João Alfredo e também seu projeto de lei, apesar de não contabilizados ou estudados por Alonso (2002), pelo fato de o estadista ser membro do Partido Conservador, podem se inserir nesse contexto.

Mesmo não citando nenhum dos inúmeros autores europeus ou norteamericanos que foram explorados como ferramentas por estes intelectuais brasileiros, o que confeririam certo grau de legitimidade aos argumentos defendidos pelos autores, como apontado por Carvalho (1998), João Alfredo se inseria em todo o debate das grandes temáticas do fim do século XIX. Alonso (2002) dá alguns exemplos dos temas recorrentes nestes debates oitocentistas: experimentação de novas formas de organizações político-administrativas, crise da economia agrária, ampliação da cidadania, reorganização do regime de trabalho e modernização.

Tratando de reformas dentro da ordem saquarema durante a crise do Império, Alonso (2002) ressalta a questão da reorganização do regime de trabalho, aponta qual seria sua solução e qual a divergência entre o que os conservadores e aqueles que contestavam as instituições imperiais pensavam:

A solução para a questão do trabalho imbricava com o ensino. Os grupos contestadores eram todos acordes quanto à premência de educar o povo tanto para a economia como para a política. E nisso estava sua grande distância com os saquaremas, que protelaram sempre a generalização do acesso às letras, mantendo a centralização do sistema de ensino. Os contestadores almejavam ampliar a abrangência do público educado liberalizando o direito de abrir escolas: a iniciativa privada iria onde os braços estatais nunca lograram chegar. Mas o Estado deveria ainda prover parte do empuxe civilizatório, 
responsabilizando-se pela educação básica para a cidadania e a educação técnica para o mercado de trabalho. (ALONSO, 2002, p. 251).

Analisando tudo aquilo proposto por João Alfredo em seus discursos e no projeto de lei para reformar a educação primária e secundária no Império, e ainda comparando com esta citação da autora, destacam-se pontos de contato entre seu projeto de reforma e as reivindicações dos contestadores, fazendo com que o estadista se encontre junto a estes citados, e não supostamente junto aos conservadores, mesmo fazendo parte de toda a lógica das instituições saquaremas e usufruindo de seus privilégios.

Enquanto parcela de intelectuais e políticos defendiam uma reforma moderada, que se realizasse dentro da ordem, como a do próprio João Alfredo, outros defendiam a implementação da República em solo brasileiro, sendo para os republicanos a monarquia e as instituições imperiais o principal obstáculo para o desenvolvimento brasileiro. É nesse movimento de crise a partir de 1870 que se estabelece uma cisão dentro do próprio Partido Conservador, enquanto o movimento republicano cresce em largas medidas.

Lynch (2012), em estudo de caso de Joaquim Nabuco, outro importante político do Segundo Reinado e contemporâneo a João Alfredo, diz:

Nada há que indique que o processo de mudança social em curso exigisse a instauração da República, ou seja, que ele não pudesse ter-se operado sob o signo do Império reformado, federalizado, na forma de uma "república velha coroada". (LYNCH, 2012, p. 283).

O mesmo autor dá ainda exemplos de reformas ocorridas durante 0 período imperial brasileiro, inclusive a própria Lei do Ventre Livre, de 1871, a qual João Alfredo se inseria como Ministro do Império. Costa (1999) aponta também a tentativa de reforma de Ouro Preto, em julho de 1889, na tentativa de frear o movimento republicano, que também não é bem sucedida.

Para Joaquim Nabuco, segundo Lynch (2012), por motivos de evitar a implantação de uma "pseudorrepública", como o eram outros países latinoamericanos caracterizados pela "anarquia da guerra civil" e pela "tirania do governo pessoal", a monarquia deveria se manter para desenvolver e bem estruturar a sociedade brasileira, surtindo "efeitos republicanos" e democráticos. Analisando bem os partidos republicanos, Joaquim Nabuco identifica como eles se tornaram classistas, sendo o ideal republicano defendido por grandes 
latifundiários e sujeitos que já usufruíram dos privilégios proporcionados pelo Império anteriormente.

João Alfredo que sempre manteve uma relação muito próxima com Joaquim Nabuco durante o Segundo Reinado, nunca se expressou da mesma maneira quanto ao movimento republicano, apesar de protestar contra o jacobinismo causado pela ditadura florianista na Primeira República em correspondências trocadas com o próprio Nabuco ${ }^{17}$. Porém, tendo em vista todo seu empenho em reorganizar o ensino primário e secundário do Império e os objetivos a que o estadista desejava serem alcançados com sua reforma educacional, pode se destacar seu desejo em desenvolver política e economicamente a sociedade brasileira, porém sem acabar com as instituições vigentes do Império, como apontado por Alonso (2002) ${ }^{18}$.

Levando-se em consideração o pensamento de Joaquim Nabuco em relação à implementação de uma República onde a população não estivesse completamente preparada para um governo democrático ${ }^{19}$, e o empenho de intelectuais em difundir o "espírito da moralidade" 20 através da instrução, como se evidencia nos discursos e no projeto de reforma educacional de João Alfredo, ressalta-se os diferentes obstáculos para o desenvolvimento brasileiro de acordo com a visão de cada um dos lados políticos do Império.

Enquanto para estes conservadores "moderados", como categorizados por Alonso (2002), o grande empecilho para o desenvolvimento do projeto Nação que ampliasse a cidadania, acabasse com os problemas da escravidão e das relações de trabalho no país, e que desenvolvesse o capitalismo industrial como nos países centrais de referência, seria a falta de instrução do povo. Já para os liberais, principalmente aqueles mais radicais, o grande obstáculo seria a monarquia e as instituições imperiais vigentes. Com a República instaurada, tudo se acertaria mais facilmente e a bonança difundir-se-ia pelas terras brasílicas.

\section{CONCLUSÃO}

Com o estudo de caso de João Alfredo, de seus discursos presentes em relatórios políticos e de seu projeto de lei, destaca-se como o estudo daqueles que se inseriam nas instituições vigentes do Império colaboram não só para a história da Educação, mas também para a história do Brasil em geral. Além disso, seu posicionamento como político a todo o tempo se direciona para uma modernização calculada da sociedade brasileira, tendo o ensino como um de

\footnotetext{
17 Revista do Instituto Histórico e Geográfico Brasileiro, Pedro Moniz de Aragão, Cartas de Joaquim Nabuco a João Alfredo (n. -257, p. 201, 1962)

${ }^{18}$ Ideais em Movimento: a geração 1870 na crise do Brasil Império $(p .78,2002)$

${ }^{19}$ Christian Lynch, O Império é que era a República: a monarquia republicana de Joaquim Nabuco (p. 284, 2012)

20 Idem, p. 294
} 
seus pilares fundamentais. A própria educação profissional para ele toca no assistencialismo, mas vai adiante, busca desenvolver uma moral para os trabalhadores brasileiros, de forma a valorizar as profissões laboriosas antes consideradas desprezíveis e indignas, tanto pela herança portuguesa quanto pela escravidão, e também capacitá-los para as ciências que tangem às indústrias presentes, e àquelas que ainda virão a existir.

O que motivava João Alfredo a contestar aspectos da sociedade imperial que formavam seus pilares centrais, como a própria escravidão, e a buscar ferramentas para desenvolver não só a economia, mas o Império em geral, é todo um projeto Nação pensado por ele e por outros intelectuais. Essas ferramentas buscadas pelo estadista, como já citado, podem ser encontradas de forma bem clara em seus discursos e em seu projeto não aprovado.

Já em seu posicionamento, observa-se a distinção de obstáculos para o desenvolvimento da sociedade brasileira de acordo com cada espectro político. Enquanto para uns, o Império em si atrasava a prosperidade destinada ao país, para outros, a falta de "pão de espírito" do povo, ou seja, sua instrução generalizada, poderia anular qualquer tentativa democrática em território brasileiro, por mais republicana que fosse.

\section{REFERÊNCIAS}

ALONSO, Angela. Ideias em movimento: a geração de 1870 na crise do Brasil Império. São Paulo: Paz e Terra, 2002.

ANDRADE, Manuel Correia de. João Alfredo, o estadista da abolição. Recife: FUNDAJ, Editora Massangana, 1988.

BARBOSA, Rui. Reforma do ensino secundário e superior. Obras completas. Vol. IX, tomo I. Rio de Janeiro: Ministério da Educação e Saúde, 1942.

BASTOS, Maria Helena Câmara. A Instrução Pública (1872-1875/1887-1888): Permuta de luzes e ideias. Os editoriais de Alambary Luz. Fortaleza: ANPUH XXV SIMPÓSIO NACIONAL DE HISTÓRIA, 2009. Disponível em: http://anais.anpuh.org/wp-content/uploads/mp/pdf/ANPUH.S25.0250.pdf. Acesso em: 28 de Junho 2016.

BLAKE, Sacramento. Verbete João Alfredo Corrêa de Oliveira. In: Diccionario bibliográphico brazileiro. Vol. 3. Rio de Janeiro: Typographia Nacional, 18831902, p. 315-316.

CARVALHO, José Murilo de. A construção da ordem: a elite política imperial; Teatro de sombras: a política imperial. Rio de Janeiro: Civilização Brasileira, 1999.

CARVALHO, José Murilo de. História intelectual no Brasil: a retórica como chave de leitura. Topoi (Rio J.), Rio de Janeiro, v. 1, n. 1, p. 123-152, Dec. 2000 . Disponível em: 
http://www.scielo.br/scielo.php?script=sci_arttext\&pid=S2237101X2000000100123\&lng=en\&nrm=iso. Acesso em: 28 de Junho 2016.

CHAMON, Carla S. Escolas de Artes e Ofícios Mecânicos em Minas Gerais. Cadernos de História da Educação, v. 13, p. 569-591, 2014.

COSTA, Emília Viotti da. Da Monarquia à República: momentos decisivos. 7. ed. São Paulo: Fundação Editora da UNESP, 1999.

CUNHA, Luiz Antonio. $O$ ensino de ofícios artesanais e manufatureiros no Brasil escravocrata. 2. ed. São Paulo: UNESP, Brasília: FLACSO Brasil, 2005.

FONSECA, Celso Suckow da. História do ensino industrial no Brasil. Rio de Janeiro, 1961.

GALVÃO, Ana Maria de Oliveira; Lopes, Eliane Marta Teixeira. Território Plural: a pesquisa em história da educação. São Paulo: Ática, 2010.

LYNCH, Christian. Da Monarquia à Oligarquia: História Institucional e pensamento político brasileiro (1822 - 1930). São Paulo: Alameda, 2014

LYNCH, Christian. O Império é que era a República: a monarquia republicana de Joaquim Nabuco. São Paulo: Lua Nova, 2012.

MACHADO, Maria Cristina Gomes; SILVA, Josie Agatha Parrilha. Os projetos de reforma da escola pública propostos no Brasil entre 1870 e 1880.

Revista HISTEDBR, 2007. Disponível em:

http://www.histedbr.fe.unicamp.br/revista/edicoes/25/doc01_25.pdf. Acesso em: 28 de Junho 2016.

MALHEIRO, Ângela. O Poder, a palavra e a ação: os discursos políticos como fonte histórica. Lisboa: Universidade Nova de Lisboa, 2015. Disponível em: https://ww.academia.edu/11856646/O_PODER_A_PALAVRA_E_A_A\%C3\%87 \%C3\%830_os_discursos_pol\%C3\%ADticos_como_fonte_hist\%C3\%B3rica. Acesso em: 28 de Junho de 2016.

MOACYR, Primitivo. A instrução e as provincias: subsídios para a história da educação no Brasil 1834-1889: volume 1: Das Amazonas às Alagoas. São Paulo: Companhia Editora Nacional, 1939.

OLIVEIRA, João Alfredo Corrêa de. Minha Meninice. Revista do Instituto Arqueológico, Histórico e Geográfico Pernambucano, vol. XLII, Recife, 1953, e Suplemento da Tribuna de Petrópolis, no 3 - Petrópolis, Julho de 1949.

PATTO, Maria Helena Souza. "Escolas cheias, cadeias vazias: nota sobre as raízes ideológicas do pensamento educacional brasileiro". Estud. av., São Paulo, v. 21, n. 61, p. 243-266, Dec. 2007. Disponível em: http://www.scielo.br/scielo.php?script=sci_arttext\&pid=S010340142007000300016\&lng=en\&nrm=iso. Acesso em: 28 de junho de 2016.

SANTOS, Jaime. A trajetória da educação profissional. In: LOPES, E. M. T.; FARIA FILHO, L. M.; VEIGA, C. G. (Orgs.) 500 anos de educação no Brasil. Belo Horizonte: Autêntica, 2000, p. 205-224.

SOUZA FILHO, Tarquínio de. O Ensino Technico no Brasil. Rio de Janeiro: Imprensa Nacional, 1887. 
TORRES, João Camillo de Oliveira. Os construtores do Império. São Paulo: Nacional, 1968.

VEIGA, Cynthia Greive. História da Educação. São Paulo: Ática, 2007. 